\title{
Stock Market, Interest Rate and Exchange Rate Risk Effects on non Financial Stock Returns During the Financial Crisis
}

\author{
Aloui Mouna ${ }^{1}$ - Jarboui Anis ${ }^{2}$ \\ Received: 21 January 2015 / Accepted: 17 September 2015 / \\ Published online: 19 October 2015 \\ (C) The Author(s) 2015. This article is published with open access at Springerlink.com
}

\begin{abstract}
In this paper, we examine the sensitivity of nonfinancial sector stock returns to the market, exchange rate risk, and interest rates in two nonfinancial sectors (technology and industry) in eight countries, including various European economies, the USA and China, over the period 2006-2009. We also test for the presence of causality-in-mean and volatility spillovers. The empirical results show that the stock market returns, interest rate, and exchange rate in most cases have a significant effect (positive and negative) during crisis. As for the three types of risk, these are found to play a role mainly in the industry sector. These empirical insights are in most cases of volatility spillovers occurring from market return to sectoral returns in the industry sector in European economies, though there are also some instances of the interest rate and exchange rate spillovers, both in Europe and in the USA, during the crisis.
\end{abstract}

Keyword Exchange rate $\cdot$ Interest rate $\cdot$ Multivariate GARCH $\cdot$ Volatility

JEL Classification $\mathrm{C} 32 \cdot \mathrm{G} 12$

\section{Introduction}

Understanding the linkage between the interest rate, the exchange rate, the stock market index, and the nonfinancial sector has been of special importance in recent years as a

Aloui Mouna

aloui.fsegs2014@gmail.com

Jarboui Anis

anisjarboui@yahoo.fr

1 Department of Financial and Accounting, University of Faculty Economics and Management of Sfax, Sfax, Tunisia

2 Department of Financial and Accounting, Universities Higher Institute of Business Administration of Sfax, Sfax, Tunisia 
consequence of the liberalization of financial markets and the technological advancement, shifts in monetary policy regimes, portfolio management, and risk management, and it may be, therefore, of special interest rate and exchange rate to investors and portfolio managers. The link between the interest rate, exchange rate, stock returns, and nonfinancial sectors is based on the financial theory. In this regard, according to survey evidence by Graham and Harvey (2001), interest rate risk is ranked by US firm managers as the second most relevant financial risk factor, only behind credit risk.

However, in the recent years, the liberalization of financial markets and the technological advancement have increased the nexus between the exchange rate, interest rates, and stock return. The relationship between the interest rate, exchange rate, stock returns, and nonfinancial sectors has given rise to a prolific research activity over the past few decades. In this context, Griffin and Stulz (2001) show that there is a relationship between the exchange rate movements and industry competition regarding the stock returns. A few studies on the link between the interest rate, exchange rate, stock returns, and nonfinancial sectors are based on the financial sector (see Bartram (2002) and Saunders and Yourougou (1990)). Jorion (1991) showed that the foreign exchange exposure is across industries but does not identify a significant effect on the financial stocks.

In recent research, Alin Marius Andrieș et al. (2014) have found very clear results of a phase difference of lead-lag relationship between the stock prices, the exchange rates, and the interest rates. However, concerning the relationship between the interest rate, exchange rate, stock returns, and both financial and nonfinancial sectors, only few studies have been conducted to examine the joint movements of all three variables (Hamrita and Trifi 2011; Mok 1993). Mojisola et al. (2011) showed that the stock returns of UK industries were very much affected by the long-term interest rate risk, the exchange rate risk, or even the short-term interest rate risk.

Our paper is different from the earlier studies in several respects. First, we focus on nonfinancial sector returns, while most studies focus on the banking sector returns. The impact of the interest rate fluctuations on the market value of companies has received a great deal of attention in the literature, although much of the empirical research has focused on financial institutions because of the particularly interest rate-sensitive nature of the banking business (Flannery and James 1984; Staikouras, 2003 and 2006). Nevertheless, interest rate variations may also exert a significant influence on nonfinancial corporations, mainly through their effect on the financing costs and the value of financial assets and liabilities held by these firms. Second, no previous research has examined the connection between the interest rates and stock prices at the industry level and technological sector by employing a four-variate generalized autoregressive conditional heteroscedastic (GARCH)-M framework method. However, the analysis on an industry basis and technological sector are appropriate because market aggregation may hide significant differences among industries and technological sector in terms of interest rate sensitivity.

Third, the previous research implicitly assumes that the financial sector is work studying because it is considered as a crucial factor of the financial crisis and the volatility of stock returns such that the banking sector expects them to improve the efficiency of the economy in general and the financial sector in particular. Besides, in this context, we instead interpret the changes in the nonfinancial sector volatility of stock returns based on the available evidence on the corporate governance 
characteristics in the European, the US, and the Chinese economies, over the period 2006-2009 during the financial crisis. Moreover, our sample period covers 2006-2009, during which there were several significant exogenous shocks, the US subprime mortgage crisis (2005-2006), and the global financial crises (2007-2009). We consider the effect of structural breaks in the stock returns, because the stock market is closely correlated with an economic system, and the impact of external factors is inescapable and should attract attention. Finally, most studies use an event study approach, but we employ a four-variate GARCH-in-mean model in order to capture the time-varying volatility in stock returns while most studies employed a GARCH univariate model.

Most studies rely heavily on the GARCH univariate model of estimation, with an emphasis on the sensitivity of stock returns and changes in exchange rate of nonfinancial sector returns and volatilities (Prabhath and Tsui (2008); Elyasiani and Mansur 1998; Faff et al. 2005; Kasman et al. 2011).

In this context, the present paper contributes to the existing literature on the following aspects. First, our study is the most up to date comprehensive comparative investigation to date in this area of the literature. Actually, as it includes Europe, USA, and China and provides evidence for two different nonfinancial sectors (industry and technological sector). Most other studies focus on nonfinancial sector or type of risk a single of country (see Prabhath and Tsui 2008; Lee et al. 2013) which allow for both types of risk mainly the studies of the Japanese and the industrial sectors (see Prabhath and Tsui 2008). Second, we carry out our extensive analysis using an appropriate econometric methodology (a four-variate GARCH-M framework) which enables us to jointly model the nonfinancial sector, the stock market, the interest rate, and the exchange rate risk by estimating their conditional volatilities. However, earlier studies often consider only the variables in levels (see again Pablo et al. 2014, for Spain) or changes in the level of interest and/or exchange rates (see, e.g., Korkeamäki 2011, for Europe). Early contributions mainly focused on interest rate factors and invariably assumed a constant variance (see Stone 1974, Chance and Lane 1980, and Bae 1990). Choi et al. (1992) included exchange rate risk as well. Following new developments in econometrics, the use of ARCH/GARCH-type models to account for time variation in the conditional variance became common (Elyasiani and Mansur 1998; Faff et al. 2005; Kasman et al. 2011; etc.). Elyasiani and Mansur (1998) were the first to analyze the bank returns by using a GARCH-M specification, in which the mean returns are explicitly affected by the conditional variance, the effects of time-varying risk premia being incorporated into the model in this way. A multivariate GARCH approach is followed by Elyasiani and Mansur (2004). These authors investigated the sensitivity of the bank stock returns in the USA to short- and long-term interest rates in turn. A few studies combined both interest and exchange rate risk (see, e.g., Choi et al. 1992; Choi and Elyasiani (1997); Koch and Saporoschenko 2001; and Joseph 2003). Moreover, no previous research has examined the connection between the interest rates, the exchange rate, and the stock prices at the industry level in the technological sectors by employing multivariate GARCH methods.

The remainder of the paper is structured as follows. "Review Literature" briefly reviews the relevant related literature, followed by "Data and Model Specification" that is going to outline the econometric modeling approach and describes the data used, 
"Hypotheses Tested" discusses the tested hypotheses, "Empirical Results" depicts the empirical findings, and the final "Conclusion" holds the concluding remarks and offers some policy implications.

\section{Review Literature}

The nexus between the exchange rate, interest rates, and stock return has been a subject of large research over the past few decades. This research can be categorized into three strands.

\section{Relationship Between Interest Rate and Stock Return of Nonfinancial Sector}

A large number of studies have focused on the interest rates on the financial stock returns (see Flannery et al. 1997; Lajeri and Dermine 1999a; Elyasiani et al. 2007; and others). There are few studies that dealt with the relation between the interest rate and the stock return of nonfinancial sector. Bartram (2002) provided empirical evidence that the interest rate variations may also exert a significant influence on nonfinancial corporations, principally through their effect on the financing costs and the value of financial assets and liabilities held by these firms.

In the same vein, Ferrer et al. (2010) pointed out that the effect of the interest rate is sensitive to the nonfinancial sectors (industries technology). He has included in this area general reports about a significant negative effect of changes in the market interest rates on the stock returns of nonfinancial companies.

However, there is a considerable attention in literature about the significant and negative relation between the interest rate and the stock return of both financial and nonfinancial sectors (see Dinenis and Staikouras 1998; Flannery and James 1984). In this context, Pablo et al. (2014) showed that the Spanish industries exhibit, in general, significant interest rate sensitivity, although the degree of the interest rate exposure differs considerably across industries depending on the time horizon under consideration.

In other words, Chien-Chiang Lee et al. (2013) found a bi-directional dynamical causal relationship between the industry returns and stock market returns. They also stated that the consumer service industry returns have a significant power in explaining the movements of the market returns.

\section{Relationship Between the Exchange Rate and Stock Returns of the Nonfinancial Sector}

Modeling exchange rate exposure has been an important growing area of research in the last decade. The second strand of studies has examined the impact of the exchange rate and stock returns on the nonfinancial sector. Jorion (1991) found that the foreign exchange rate exposure is different across industries, but he does not identify a significant effect on financial stocks. Prabhath and Tsui (2008) employed a bivariate GJR-GARCH model to examine all such aspects of the exchange rate exposure of sector indexes in the Japanese industries and found significant evidence of exposed returns and an asymmetric conditional volatility of exchange rate exposure. Moreover, 
Dai Wensheng et al. (2010) using the GARCH model found that the exchange rate risk faced by companies can be reflected mainly by the exchange rate.

Using univariate and multivariate GARCH-type models to investigate the properties of conditional volatilities of the stock returns and exchange rates, as well as their empirical relationship, Walid Chkili et al. 2012 found that bilateral relationship between stock and foreign exchange markets is highly significant in France and Germany. In addition, in a recent paper, Inci and lee (2014) showed that there is an effect of the stock return changes and exchange rate changes in eight major countries and nine major sectors of their economies, and pointed out the causal relationships and highlighted the dynamic effects by using lagged variables. They found that the evidence of Granger causality from the exchange rate changes to the stock returns, and vice versa.

Although the theoretical literature suggests causal relationships between stock prices and exchange rates, the empirical evidence is rather weak. Pan et al. 2007 found significant causal relationships from exchange rates to stock prices in Hong Kong, Japan, Malaysia, and Thailand before the 1997 Asian financial crisis. They also found a causal relationship from the equity market to foreign exchange market for Hong Kong, Korea, and Singapore. Furthermore, while no country showed a significant causality from the stock prices to the exchange rates during the Asian crisis, a causal relationship from the exchange rates to the stock prices is found for all the countries except for Malaysia. In their study of Istanbul stock exchange (ISE), Acikalin and Seyfettin Unal (2008) showed that the use of the co-integration test and vector error correlation model assumes that exchange rate has a direct long run equilibrium relationship with the stock market index. Findings from the study revealed two ways of causalities between the two variables, which implies that prediction of ISE is possible using the past information on the moves of the exchange rate.

\section{Relationship Between the Exchange Rate, the Interest Rate, and the Stock Return of the Nonfinancial Sector}

While most empirical studies concerning the pricing of bank stock return mainly focus on the pricing of the interest rate, very few published papers explicitly investigated the joint interaction of the exchange rates and interest rates on the nonfinancial sector. Ayșe and Kutan (2007) pointed out to the changes in daily financial sector stock returns in Indonesia, Korea, and Thailand in response to IMF-related news during the Asian crisis and compared them with those in the nonfinancial sectors. However, Stuart Hyde (2007) indicated the sensibility of the stock returns at the level market industry, the exchange rate, and the interest rate shocks in the four major European economies (France, Germany, Italy, and the UK). They also found that industry portfolios have significant exposures to these risks. Alin Marius Andrieş et al. (2014) used the crosswavelet power, the cross-wavelet coherency, and the phase difference methodologies. They found that the stock price and the exchange rates are linked. Moreover, those stock price movements are lagging both to the exchange rate and interest rate fluctuations. The authors also indicated that the interest rate and the stock price movements are even clearer, especially after 2006, which suggests that the stock market follows the interest rate signals.

The present study is different from the previous studies in the following way. First, this paper uses a four-variate value at risk (VAR)-GARCH $(1,1)$-in-mean model to 
study the four-way linkages between the nonfinancial sector index, the stock market index, the interest rate, and the exchange rate for a panel consisting of eight countries. However, to the best of our knowledge, none of the empirical studies has focused on investigating the four-way linkages between the nonfinancial sector index, the stock market index, the interest rate, and the exchange rate, especially the combination of nonfinancial sector using four-variate VAR-GARCH $(1,1)$-in-mean model framework. The model allows us to examine at the same time the impact of the stock market index, the interest rate, and the exchange rate on the nonfinancial sector index. Second, we use a four-variate VAR-GARCH $(1,1)$-in-mean model because it allows not only for timevarying conditional variances but also for a time-varying conditional covariance. Alternatively, the VAR-GARCH $(1,1)$-in-mean model is based on the multivariate GARCH (1,1)-Baba, Engle, Kraft, and Kroner (BEKK) representation proposed by Engle and Kroner (1995).Engle and Kroner (1995) argued that the main advantage of the BEKK representation over the ones introduced earlier is that the positive definiteness of the covariance matrix.

\section{Data and Model Specification}

In this paper, we examine the three-way linkages between the stock returns, the nonfinancial sector market, the interest rate, and the exchange rate risk for eight countries, namely Germany, the USA, Greece, the UK, France, Spain, Italy, and China. The most widely used for each country, two non financial stock indices (Technology and industry) are regressed on a stock market returns, interest rate, and exchange rate risk in the non financial sector. the sample period runs from January 2006 through September 2009. Therefore, the relationships between the three variables are worth investigating by considering them a four-variate VAR-GARCH $(1,1)$-in-mean model in a modeling framework. The interest rates were obtained from the IMF's International Financial Statistics (IFS); the stock market returns were obtained investing the exchange rates extracted from the PACIFIC exchange rate database.

We adopt a model of a family of multivariate GARCH models. The GARCH model was first proposed by Bollerslev et al. (1988). Their model provides a general framework for multivariate volatility modeling but requires a large number of parameters to be estimated. More specifically, we apply a four-variate VAR-GARCH-in-mean framework with the BEKK representation proposed by Engle and Kroner (1995) to model and test for market spillovers in means and variance of the stock returns and the market spillovers from second to first moment (GARCH-in-mean effects). The VAR-GARCH model is based on the multivariate GARCH $(1,1)$-BEKK representation proposed by Engle and Kroner (1995). In this perspective, an important extension of the generalized autoregressive conditional heteroscedastic $(\mathrm{GARCH})$ is suggested by Bollerslev (1986). The GARCH $(p, q)$ is a form of the ARMA model on the conditional variance. The conditional variance of the study variable is determined by the square of the error terms $p$ and $q$ past conditional variances delayed. The GARCH models have proven their ability to capture the following properties: The first is that volatility clustering large variations tend to be followed by large changes and small changes by small variations. These univariate $\mathrm{ARCH} / \mathrm{GARCH}$ models have now been extended to encompass multivariate GARCH $(\mathrm{MGARCH})$ models which are capable of capturing 
the following salient features of the stock market returns: leptokurtosis, volatility clustering, and leverage effects, which otherwise cannot be captured using univariate ARCH/GARCH models (Schwert 1990; Bera and Higgins 1993; Brooks 2002). While the constant correlation assumption provides a convenient MGARCH model of estimation, some studies found that this assumption is not supported by some financial data. Thus, there is a need to extend the MGARCH models to incorporate time-varying correlations and yet retain the appealing feature of satisfying the positive-definite condition during the optimization. Engle and Kroner (1995) proposed a class of MGARCH model called the BEKK (named after Baba, Engle, Kraft, and Kroner) model. Engle and Kroner provided some theoretical analyses of the BEKK model and related them to the vech representation form. In another approach, Lien et al. (2001) reported difficulties in getting convergence when using the BEKK model to estimate the conditional variance structure of the spot and future prices. The VAR-GARCH model answers whether the BEKK specification (i.e., time-varying) or the Bollerslev specification (constant) is more appropriate in these studies.

We model the joint process governing the nonfinancial sector index, the stock market index, the interest rate, and the exchange rates with a four-variate VARGARCH (1,1)-in-mean model. First, the model (four-variate VAR-GARCH $(1,1)$ ) is based on the multivariate GARCH $(1,1)$-BEKK representation proposed by Engle and Kroner (1995). Second, the multivariate extension of the univariate $\operatorname{GARCH}(p, q)$, even for low dimensions of $N$ and small values of $p$ and $q$, the number of parameters is very large; for $N=5$ and $p=q=1$, the unrestricted version of (1) contains 465 parameters. In a GARCH $(1,1)$ model, it was the only specification for which the estimation procedure converged to statistically significant parameter estimates consistent with a stable model. Thus, we introduced the multivariate GARCH model in the style of BEKK proposed by Engle and Kroner (1995). The parameters in the conditional variance-covariance matrix can be modeled in several ways. One way is to model it as a multivariate BEKK GARCH process. BEKK formulation enables us to reveal the existence of any transmission of volatility from one market to another (Engle and Kroner 1995). Besides, it has few parameters and ensures positive definiteness of the conditional covariance matrix needed for quadratic non-negative estimated conditional variance (Engle and Kroner 1995). This paper applies the four-variate GARCH-BEKK model to capture effectively the cross volatility spillovers between stock markets in China, Europe, and the USA.

In our study, we applied a four-variate VAR-GARCH-in-mean, which is a model based on the multivariate GARCH $(1,1)$-BEKK representation proposed by Engle and Kroner (1995) to model and test for cross-market spillovers in means and variances of stock and the cross-market spillovers from second to first moments (GARCH-in-mean effects). The parameter matrices for the variance Eq. (2) are given by $\mathrm{C} 0$, which is restricted to be upper triangular and two matrices A11 and G11. Each of these two matrices has four zero restrictions as we are focusing on volatility spillovers (causalityin-variance) running from the stock market index, the interest rate, and the exchange rate volatility to the nonfinancial sector volatility.

This approach builds upon and expands existing studies such as that of John Beirne et al. (2009). The use of a GARCH-in-mean specification enables us to estimate crossmarket spillovers from the second to the first moments. This is a key contribution of the present study, which differentiates it from the earlier one by Beirne et al. (2009) and 
other related papers. An appealing property of the GARCH-BEKK is that the model ensures positive and definite conditional covariance matrix. In order to reduce the number of parameters estimated in the GARCH-BEKK model, restrictions such as symmetricity and diagonality are often imposed.

We represent the joint process governing the stock returns in the nonfinancial sectors to the market, the interest rate, and the exchange rate risk by a four-variate VARGARCH (1,1)-in-mean process. In its general specification, the model has the following from

$$
x_{t}=\alpha+\beta x_{t-1}+\gamma H_{t}{ }^{1 / 2}+\mu_{t}
$$

$x_{t}=$ nonfinancial returns, stock returns, interest rate, exchange rate, and the residual vector $\mu_{t}\left(e_{1, t}, e_{2, t}, e_{3, t}, e_{4, t}\right)$ is the four-variate and normally distributed $\mu_{t} \mid I_{t-1} \sim\left(0, H_{t}\right)$ with its corresponding conditional variance-covariance matrix given by

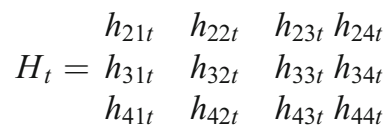

The parameter specification of the mean return Eq. (1) is defined by the constant $\alpha=\left(\alpha_{1}, \alpha_{2}, \alpha_{3}, \alpha_{4}\right)$, the autoregressive term $\beta=\left(\beta_{11}, \beta_{12}, \beta_{13}, \beta_{14}\left|0, \beta_{22}, 0,0\right| 0,0\right.$, $\left.\beta_{33}, 0 \mid 0,0, \quad \beta_{44}\right)$, and the GACH-in-mean term $\gamma=(1 / 1,1 / 2,1 / 3$, $\left.1 /{ }_{4}|0,0,0,0| 0,0,0,0 \mid 0,0,0,0\right)$ which appears in Eq. (1) only. The parameter matrices for the variance Eq. (2) are given by $C_{0}$, which is restricted to be upper triangular and two matrices $A_{11}$ and $B_{11}$. It should be noted that in our model, there are nine zero restrictions in the latter two matrices, as we are only interested in testing for the causality-in-variance (spillover) running from the stock market, the interest rates, and the exchange rates to the nonfinancial stock returns.

The multivariate GARCH $(1,1)$-BEKK representation proposed by Engle and Kroner (1995), which guarantee, by construction, that the variance-covariance matrices in the system are positive definite $H_{t}$, takes the following form:

$$
\begin{gathered}
H_{t}=C_{0}^{\prime} C_{0}+\left|\begin{array}{cccc}
A_{t 1} & A_{t 2} & A_{t 3} & A_{t 4} \\
0 & A_{22} & 0 & 0 \\
0 & 0 & A_{33} & 0 \\
0 & 0 & 0 & A_{44}
\end{array}\right|,\left|\begin{array}{cccc}
e_{1, t-1}^{2} & e_{1, t-1} e_{2, t-1} & e_{1, t-1} e_{3, t-1} & e_{1, t-1} e_{4, t-1} \\
e_{2, t-1} e_{1, t-1} & e_{2, t-1}^{2} & e_{2, t-1} e_{3, t-1} & e_{3, t-1} e_{4, t-1} \\
e_{3, t-1} e_{1, t-1} & e_{3, t-1} e_{2, t-1} & e_{3, t-1}^{2} & e_{3, t-1} e_{4, t-1} \\
e_{4, t-1} e_{1, t-1} & e_{4, t-1} e_{2, t-1} & e_{4, t-1} e_{3, t-1} & e_{4, t-1}^{2}
\end{array}\right| \\
\left|\begin{array}{cccc}
A_{t 1} & A_{t 2} & A_{t 3} & A_{t 4} \\
0 & A_{22} & 0 & 0 \\
0 & 0 & A_{33} & 0 \\
0 & 0 & 0 & A_{44}
\end{array}\right|\left|\begin{array}{cccc}
B_{11} & B_{t 2} & B_{t 3} & B_{t 4} \\
0 & B_{22} & 0 & 0 \\
0 & 0 & B_{33} & 0 \\
0 & 0 & 0 & B_{44}
\end{array}\right|, H_{t-1}\left|\begin{array}{ccccc}
B_{11} & B_{t 2} & B_{t 3} & B_{t 4} \\
0 & B_{22} & 0 & 0 \\
0 & 0 & B_{33} & 0 \\
0 & 0 & 0 & B_{44}
\end{array}\right|
\end{gathered}
$$

Equation (2) models the dynamic process of $H_{t}$ as a linear function of its own past values $H_{t-1}$ and past values of the squared innovations $\left(e_{1}, t-1^{2}, e_{2}, t-1^{2}, e_{3}, t-1^{2}, e_{4}, t\right.$ 
$-1^{2}$ ), allowing for own-market and cross-series influences in the conditional variance. The important feature of this specification is that it guarantees by construction that the covariance matrices in the system are positive definite.

Given a sample of $T$ observations, a vector of unknown parameters $\theta$ and a $4 \times 1$ and vector of variables $x_{t}^{2}$, the conditional density function for the models (1)-(3) is

$$
\mathrm{F}\left(x_{t} \mid I_{t-1} ; \theta\right)=(2 \pi)^{-1} I H_{t} I^{-1 / 2} \exp \left(-\left[\mu_{t}\left(H_{t}^{-1}\right) \mu_{t}\right] / 2\right)
$$

The Log-likelihood function $(L)$ is

$$
L=\sum_{t=1} T \log f\left(x_{t} \mid I_{t-1} ; \theta\right) .
$$

\section{Hypotheses Tested}

A number of hypotheses are tested on the estimated parameters and a likelihood ratio test statistic (LR) is computed on the unrestricted and restricted models, where $L R=-2$ $\left(L_{r}-L_{u}\right) \sim x^{2}(K)$. The tests undertaken include individual hypotheses at degrees of freedom $(k)$ in the range of one to three depending on the number of the considered restrictions $(k)$. The main restrictions tested are (i) the effect of the stock market returns, the interest rates, and the exchange rates on the mean returns in each financial sector; (ii) the effect of changes in the second moment of the stock market returns, the interest rates, and the exchange rates on the mean returns in each financial sector; and finally (iii) the volatility spillovers from the stock market returns, the interest rate, and the exchange rate returns to volatility of returns in each nonfinancial sector.

Tests of no GARCH-in-mean effect:

H1: No market return volatility effect in mean $Y_{1 / 12}=0$

H2: No short-term interest rate volatility effect in mean $\mathrm{Y}_{1 / 13}=0$

H3: No long-term interest rate volatility effect in mean $\mathrm{Y}_{1 / 14}=0$

H4: No exchange rate volatility effect in mean $\mathrm{Y}_{1 / 15}=0$

$\mathrm{H} 1$ to $\mathrm{H} 4$ test the sensibility of the level of the relevant nonfinancial sector index returns to volatility in the market returns, the short-term interest rate, the long-term interest rate, and the exchange rates.

Test no causality-in-mean effect:

H5: No market return effect $\beta_{1 / 12}=0$

H6: No short-term interest rate effect $\beta_{1 / 13}=0$

H7: No long-term interest rate effect $\beta_{1 / 14}=0$

H8: No exchange rate effect $\beta_{1 / 15}=0$

$\mathrm{H} 5$ to $\mathrm{H} 8$ test the sensitivity of the nonfinancial sector index returns to the market returns, the short-term interest rate, the long-term interest rate, and the exchange rates. 


\title{
Empirical Results
}

\section{Results of the GARCH-BEKK Model During the Financial Crisis}

\author{
Results of the Technological Sector During the Financial Crisis
}

Table 1 shows the results for all the four GARCH multivariate and the four-variate GARCH $(1,1)$-in-mean model. The finding indicates spillover effects. Let us focus first on these coefficients $\beta_{12}, \beta_{13}, \beta_{14}$, and $\beta_{15}$, which correspond respectively to the exchange rate causality, the short-term interest rate, the long-term interest rate, and the stock return causality-in-mean effects in conditional mean equation. The results indicate that the coefficients of the exchange rate have a negative and significant effect on the technological sector for most countries, except for Germany, the USA, and the UK which are positively and significantly affected (at 1 and $5 \%$ levels, respectively) in the technological sector $\left(\beta_{12}\right)$. On the other hand, $\beta_{13}$ is statistically significant (at 1 and $10 \%$ levels, respectively) in all cases with a positive and a negative effect on the technological sector. The coefficients $\beta_{14}$ are significant (at 1 and $10 \%$ levels, respectively) and positive for the USA and the UK, an effect only from the exchange rate to the technological sector. Finally, for $\beta_{15}$, we can see a negative and significant effect (at $1 \%$ level) (notably France and China) from the stock return to the financial service sector.

As for spillovers of the exchange rate, the short-term interest rate, the long-term interest rate volatility, and the stock return measured respectively by $\mathrm{Y}_{1 / 12}, \mathrm{Y}_{1 / 13}, \mathrm{Y}_{1 / 14}$, and $\mathrm{Y}_{1 / 15}$, except for Germany; the USA and France are significant at $1 \%$ and have a positive effect on the exchange volatility $\left(\mathrm{Y}_{1 / 12}\right)$. Moreover, we find that only Germany and Spain are significantly affected (at 1, 5, and $10 \%$ levels, respectively) and positively affected from the short-term interest rate $\left(\mathrm{Y}_{1 / 13}, \mathrm{Y}_{1 / 14}\right)$. As for $\mathrm{Y}_{1 / 15}$, we find that all the cases are significantly and positively affected from the stock market, except for the USA; France and the UK are not significant.

Evidence from the volatility spillovers, from the exchange rate volatility from the short-term and long-term interest rate and the stock return are measured by the parameters $A_{12}, A_{13}, A_{14}$, and $A_{15}$. The coefficients are significantly positive (notably Germany, Greece, and France) and negative for the UK, China, and Spain, an effect from the exchange volatility $\left(A_{12}\right)$ on the technological sector. We can see a significant effect (at 5 and $10 \%$ level, respectively) and a positive effect for all the cases from the short-term interest rate on technological sector except for Greece which is not significant $\left(A_{13}\right)$. We also found significant positive and negative (Germany and Spain) effects from the long-term interest rate $\left(A_{14}\right)$. We can see a negative effect for Germany and Spain but significant only from the stock return to the technological sector $\left(A_{15}\right)$.

In Table 1, the estimated results about the technological sector effect from the shortterm and long-term interest rate, the stock return, and the exchange rate of the conditional volatilities to that of the technological stock returns are measured by the parameters $B_{12}, B_{13}, B_{14}$, and $B_{15}$. We can see that the effect for Germany, the UK, and Spain is positive, but for France, it is negative. Moreover, this effect is significant only from the exchange rate conditional volatilities to that of the technological sector $\left(B_{12}\right)$. 


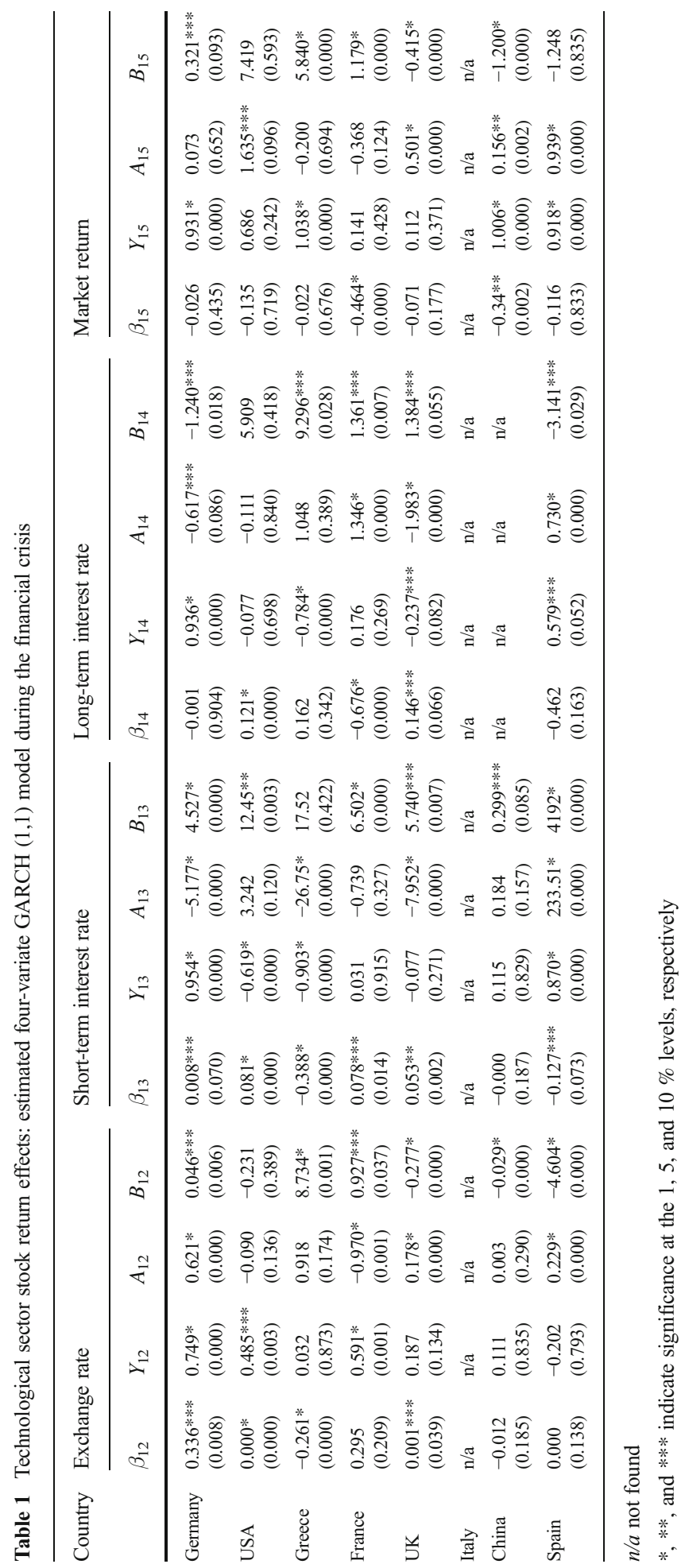


On the other hand, this effect is positive for Spain, but negative for Germany, Greece, and the UK and significant effect from the exchange rate volatility to the technological sector. Besides, there is a positive and significant effect from the short-term interest rate on the technological sector $\left(B_{13}\right)$. As for the long-term interest rate, it has a positive effect for the UK, China, and Spain from the stock return on the technological sector $\left(B_{15}\right)$.

Finally, the main results can be summarized as follows. First, it is clearly shown that the volatility of the exchange rate, the interest rate, and the stock returns is significant in most cases and has a negative and positive impact on the technological sector. Second, this finding is consistent with that in a recent study by Reilly et al. (2007) and Ferrer et al. (2010) who stated that there is a significant negative effect of the changes in the interest rates on the stock returns of the financial and nonfinancial stock return.

\section{Results of Industrial Sector During the Financial Crisis}

In Table 2, the estimated results show that the impact of the exchange rate volatility is significant (at 1,5 , and $10 \%$, respectively) with a positive and a negative effect on the industrial sector $\left(\beta_{12}, \beta_{14}\right.$, and $\left.\beta_{15}\right)$. By contrast, the short-term interest rate (notably for France and Greece) has no significant effect on the level of the industrial sector $\left(\beta_{13}\right)$.

In addition, the spillovers of the exchange rate, the short-term and long-term interest rate volatility, and the stock return causality-in-mean effects in the conditional mean equation are measured, respectively, $Y_{12}, Y_{13}, Y_{14}$, and $Y_{15}$. We can see a significant positive and negative effect from the exchange rate volatility and the short-term interest rate on the industrial sector $Y_{12}, Y_{13}$, and $Y_{14}$ but not significant in some cases. The results indicate that there is no significant volatility spillover effect from the stock return in some countries (Greece, France, the UK, and Spain) on the industrial sector $\left(Y_{15}\right)$.

The coefficient of the volatility spillovers from the exchange rate, the short-term and the long-term interest rate, and the stock return is measured by the parameters $A_{12}, A_{13}$, $A_{14}$, and $A_{15}$; we notice that this effect is statistically significant and positive at 1,5 , and $10 \%$ levels, respectively, from the exchange rate volatility to the industrial sector $A_{12}$ but insignificant for USA. However, the effect of the short-term and long-term interest rate and the stock returns on the industry sector $\left(A_{13}, A_{14}\right.$, and $\left.A_{15}\right)$ is significantly positive and negative.

The empirical results show the spillovers from the short-term and long-term interest rate, the stock return, and the exchange rate conditional volatilities. In fact, the effect from $\left(B_{12}, B_{13}, B_{14}\right.$, and $\left.B_{15}\right)$ on the industrial sector is significantly positive and negative, but also, we can find statistically insignificant in some countries.

Furthermore, the BEKK GARCH $(1,1)$ analysis revealed a considerable heterogeneity among industries in terms of the extent of the interest exposure which emerged as more vulnerable than are interest rate risk, the exchange rate, and the stock returns. This finding is in accordance with the pattern of the interest rate sensitivity reported by, among others, Mojisola et al. (2011) who showed that the stock returns of the UK industries were more affected by the long-term interest rate risk than by the exchange rate risk or even the short-term interest rate risk. Interestingly, a pattern of positive significant interest rate exposure is, however, observed at the coarsest scales for 


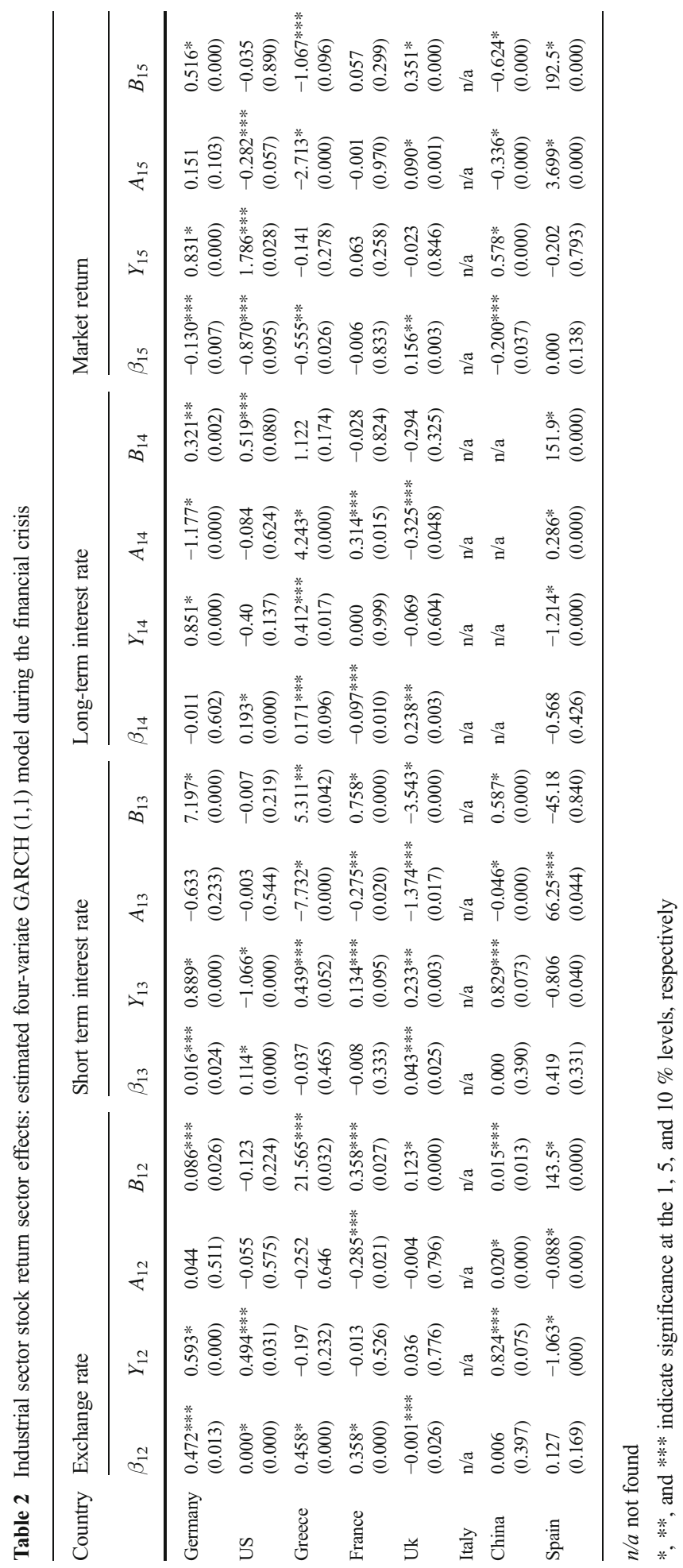




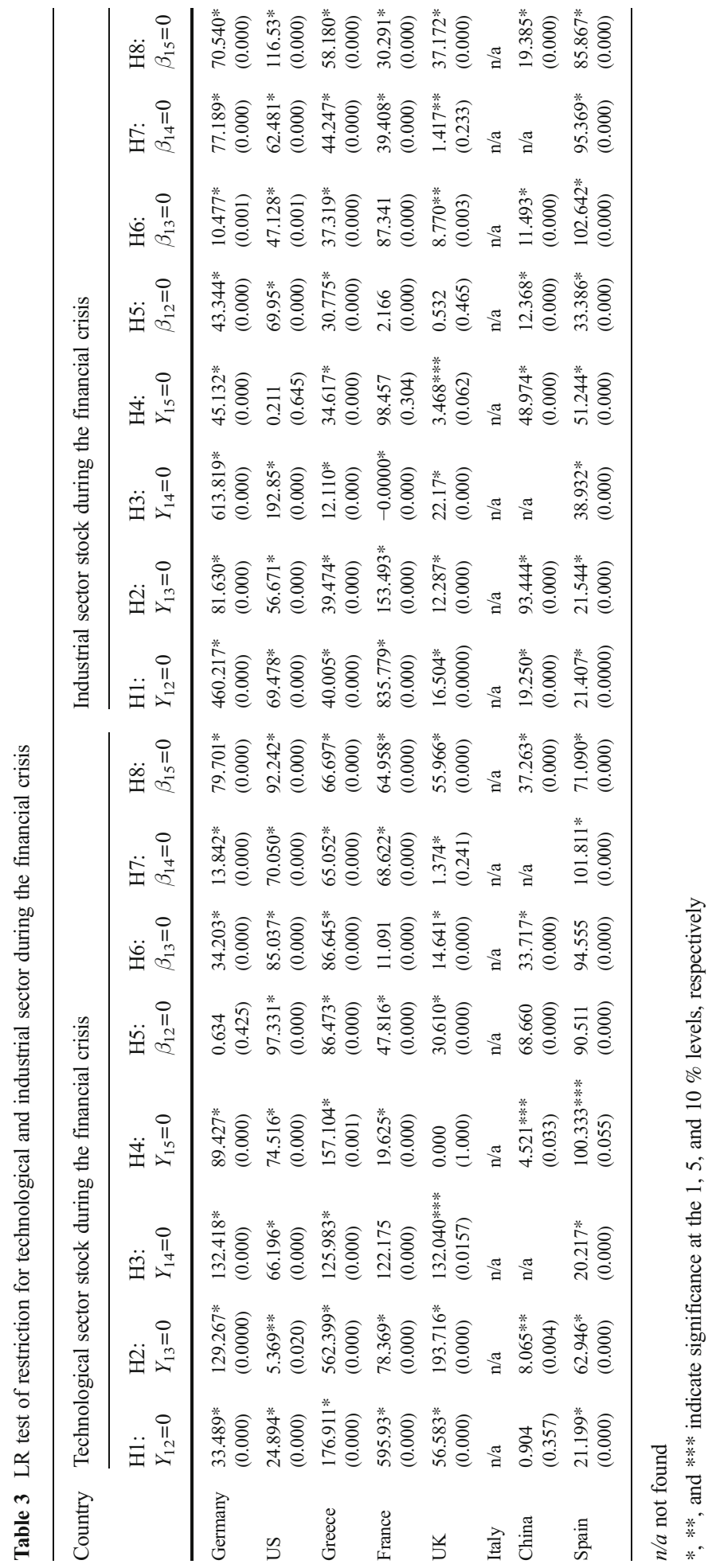


industry. A possible explanation for this finding is related to the pro-cyclical nature of the sector. Specifically, the low and relatively stable levels of interest rates for most of the study period can be interpreted as a sign of a weak economy.

\section{Results of LR Tests Restrictions for the Technological and Industrial Sector Stock Return During the Financial Crisis}

To examine the main tested restrictions, firstly, we should explain the effect of the stock market returns, the interest rates, and the exchange rates on the mean returns in each nonfinancial sector. Secondly, the effect of the stock market returns the interest and the exchange rates on the mean return changes in each nonfinancial sector.

Table 3 presents the estimated results for all the likelihood (LR) test statistics for a single coefficient restriction, $\mathrm{H} 1$ to $\mathrm{H} 8$. The finding indicates that the exchange rate, the interest rate (short-term and long-term), and the stock returns are significant at 1 and $5 \%$ in all the analyzed countries except the US industrial sector (where the stock returns are not significant, and therefore, $\mathrm{H} 4$ hypothesis is rejected). Moreover, the return process of nonfinancial sector is checked through the rejection of the null hypothesis of no effect of the exchange rate, the interest, and the stock market returns (there is not an effect in mean $Y_{12}=0, Y_{13}=0, Y_{14}=0$, and $Y_{15}=0$ ).

This is can be explained by the high sensitivity between the index returns of the nonfinancial sector (technological and industrial), market returns, interest rates, and exchange rates, which also have a positive relationship. However, the test for noncausal test effect in means is represented by $\left(\beta_{12}=0, \beta_{13}=0, \beta_{14}=0\right.$, and $\left.\beta_{15}=0\right)$. It is thought that the exchange rate, the interest, either in the short or long term, and the stock market returns in all the analyzed countries are significant at 1 and $10 \%$, with the exception of the technological sector of the UK (where the long-term interest rate is significant); hence, hypothesis $\mathrm{H} 7$ is rejected.

Therefore, it can be concluded that there is a high sensitivity between the returns of the nonfinancial sector indices (technological and industrial) and the market returns, the interest, and the exchange rates. Besides, it can be noted that, after the financial crisis, the index returns of the nonfinancial sector (technological and industrial) are on average very sensitive to the changes of the market returns and the interest and exchange rates.

However, in the German technological sector, in particular, the exchange rate is not significant, which leads us to reject hypothesis H5.

\section{Conclusion}

Over recent years, the impact of the market, the interest, and the exchange rate risk on the nonfinancial stock returns have been of special importance as a consequence of shifts in financial and technological developments in communication and trading systems. This article tackles this issue by using the GARCH-M Approach estimates over the period of the financial crisis 2006-2009. Specifically, we examine the impacts of the markets, the interest, and the exchange rate risk 
effects on the nonfinancial stock returns. We go a step further and estimate this relationship in eight countries and European, American, and China economies. Our analysis suggests that (i) there a is causal-in-mean relationship between the exchange rate, the interest rate, and the stock return in most countries; and (ii) there is a relationship between the exchange rate, the interest rate, and the stock return in volatility spillovers regarding most of the countries.

The main implications arising from our study can be presented as follows. First, the empirical results, for the estimation techniques, show that the impact of the stock market returns is as what one would expect. As for the interest and the exchange rates, the picture which emerges is not equally clear. Nonetheless, the long-term interest rates seem to have a limited effect on the nonfinancial sector. This also holds for the exchange rate effects, although, in this case, the observed pattern is more easily interpretable in terms of the foreign net position of the concerned nonfinancial institutions. Second, we find that the volatility of the exchange rate, the interest rate, and the stock returns has sometimes a positive and sometimes a negative impact on the nonfinancial sector (technology and industrial sector). Moreover, the volatility of exchange rates, the interest rates, and the stock return has a more important effect on the industrial sector of Germany, Greece, China, and the UK than of other countries that are analyzed during the financial crisis in the period 2006-2009. Third, we show that the volatility of exchange rates, the interest rates, and the stock returns is significant in most cases and has a negative and positive impact on the technological sector. On the other hand, the volatility of the exchange rates, the interest rates, and the stock return has an effect on the technological sector of Germany, France, the UK, and Spain as well as on most of the differently analyzed countries.

In this context, this paper has some policy implications. In fact, the nature of the impact the market, the interest rate, and the exchange rate risk effects on the nonfinancial stock returns could provide valuable information for portfolio management purposes both domestically and internationally. The results suggest that investors should follow the monetary policies more closely to make decisions about their investments since the interest and the exchange rates have predictive powers on the bank stock returns and volatility.

In addition, the link between the movements in the interest rates and the industrial equity returns is weak at the shortest scales, but it becomes stronger at longer horizons corresponding to low frequencies. This finding is in line with the idea that investors with long-term horizons are more likely to follow macroeconomic fundamentals, such as interest rates, in their investment decisions than investors with shorter perspectives. Therefore, it can be stated that the role of the interest rates is a key driver of the stock market performance. As expected, the linkage between the interest rate changes and the stock returns is primarily negative, suggesting that companies, in general, are favored by falls in interest rates. In addition, the BEKK GARCH $(1,1)$ analysis provides evidence of feedback effects between the interest rate, the exchange rate fluctuations, and (industry, technology sector) the equity returns at the longest scales. The evidence presented in this study may be very helpful for the assessment of potential sector-based diversification opportunities by investors, for the design and implementation of adequate exchange rate and interest rate risk management strategies by firm managers and investors, for asset allocation 
decisions by portfolio managers, and for the formulation of appropriate monetary policy measures by governments.

Open Access This article is distributed under the terms of the Creative Commons Attribution 4.0 International License (http://creativecommons.org/licenses/by/4.0/), which permits unrestricted use, distribution, and reproduction in any medium, provided you give appropriate credit to the original author(s) and the source, provide a link to the Creative Commons license, and indicate if changes were made.

\section{References}

Acikalin, S., \& Seyfettin Unal, R. A. (2008). An empirical analysis of the Istanbul stock exchange. Investment Management and Financial Innovations, 5(1), 8-16.

Andrieş, A. M., Ihnatov, L., Tiwari, A. K. (2014). Analyzing time-frequency relationship between interest rate, stock price and exchange rate through continuous wavelet. Journal of Economic Modelling.

Ayșe, Y. E., \& Kutan, A. M. (2007). MF-related announcements and stock market returns: evidence from financial and non-financial sectors in Indonesia, Korea, and Thailand. Journal of Pacific-Basin Finance Journal, 15(1), 80-104.

Bae, S. C. (1990). Interest rate changes and common stock returns of financial institutions. Journal of Financial Research, 13, 71-79.

Bartram, S. M. (2002). The interest rate exposure of non financial corporations. European Finance Review, 6 , $101-125$.

Beirne, J., Caporale, G. M., \& Spagnolo, N. (2009). Market, interest rate and exchange rate risk effects on financial stock returns: AGARCH-M approach. Quantitative and Qualitative Analysis in Social Sciences, 3(2), 44-68.

Bera, A. K., \& Higgins, M. L. (1993). ARCH models: properties, estimation and testing. Journal of Economic Surveys, 7, 305-366.

Bollerslev, T. (1986). A generalized conditional autoregressive heteroskedasticity. Journal of Econometrics, 31, 307-327.

Bollerslev, T., Engle, R., \& Wooldridge, J. M. (1988). A capital asset pricing model with time varying covariances. Journal of Political Economy, 96, 116-131.

Brooks, C. (2002). Modelling volatility and correlation, introductory econometrics for finance slide presentation.

Chance, D. M., \& Lane, W. R. (1980). A re-examination of interest rate sensitivity in the common stock of financial institutions. Journal of Financial Research, 3, 49-55.

Chkili, W., Aloui, C., Nguyen, D. K. (2012). Asymmetric effects and long memory in dynamic volatility relationships between stock returns and exchange rates. Journal of International Financial Markets, Institutions \& Money.

Choi, J. J., \& Elyasiani, E. (1997). Derivative exposure and the interest rate and foreign exchange rate risks of US banks. Journal of Financial Services Research, 12, 267-286.

Choi, J. J., Elyasiani, E., \& Kopecky, K. J. (1992). The sensitivity of bank stock returns to market, interest and exchange rate risks. Journal of Banking and Finance, 16, 983-1004.

Dinenis, E., \& Staikouras, S. (1998). Interest rate changes and common stock returns of financial institutions: evidence from the UK. European Journal of Finance, 4, 113-127.

Elyasiani, E., \& Mansur, I. (1998). Sensitivity of the bank stock returns distribution to changes in the level and volatility of interest rate: a GARCH-M Model. Journal of Banking and Finance, 22, 535-563.

Elyasiani, E., \& Mansur, I. (2004). Bank stock return sensitivities to the long-term and short-term interest rates: a multivariate GARCH approach. Managerial Finance, 30, 32-55.

Elyasiani, E., Mansur, I., \& Pagano, M. (2007). Convergence and risk-return linkages across financial services firms. Journal of Banking and Finance, 31, 1167-1190.

Engle, R. F., \& Kroner, K. (1995). Multivariate simultaneous generalized ARCH. Econometric Theory, 11, $122-150$.

Faff, R. W., Hodgson, A., \& Kremmer, M. L. (2005). An investigation of the impact of interest rates and interest rate volatility on Australian financial sector stock return distributions. Journal of Business Finance and Accounting, 32, 1001-1032.

Ferrer, R., Gonzalez, C., \& Soto, G. M. (2010). Linear and nonlinear interest rate exposure in Spain. Managerial Finance, 36, 431-451. 
Flannery, M., \& James, C. (1984). The Effect of Interest Rate Changes on the Common Stock Returns of Financial Institutions. Journal of Finance, 39, 1141-1153

Flannery, M. J., Hameed, A. S., \& Harjes, R. S. (1997). Asset pricing, time-varying risk premia, and interest rate risk. Journal of Banking and Finance, 21, 315-335.

Graham, J. R., \& Harvey, C. R. (2001). The theory and practice of corporate finance: evidence from the field. Journal of Financial Economics, 60, 187-243.

Griffin, J., \& Stulz, R. (2001). International competition and exchange rate shocks: a cross country industry analysis of stock returns. Review of Financial Studies, 14, 215-241.

Hamrita, M. E., \& Trifi, A. (2011). The relationship between interest rate, exchange rate and stock price: a wavelet analysis. International Journal of Economics and Financial Issues, 1(4), 220-228.

Hyde, S. (2007). The response of industry stock returns to market, exchange rate and interest rate risks. Managerial Finance, 33(9), 693-709.

Inci, A. C., \& Lee, B. S. (2014). Dynamic relations between stock returns and exchange rate changes. European Financial Management, 20(1), 71-106.

Jorion, P. (1991). The pricing of exchange rate risk in the stock market. Journal of Financial and Quantitative Analysis, 26, 363-376.

Joseph, N. L. (2003). Predicting returns in US financial sector indices. International Journal of Forecasting, 19, 351-367.

Kasman, S., Vardar, G., \& Tunc, G. (2011). The impact of interest rate and exchange rate volatility on banks' stock returns and volatility: evidence from Turkey. Economic Modelling, 28, 1328-1334.

Koch, T. W., \& Saporoschenko, A. (2001). The effect of market returns, interest rates, and exchange rates on the stock returns of Japanese horizontal keiretsu financial firms. Journal of Multinational Financial Management, 11, 165-182.

Korkeamäki, T. (2011). Interest rate sensitivity of the European stock markets before and after the Euro introduction. Journal of International Financial Markets, Institutions and Money, 21, 811-831.

Lajeri, F., \& Dermine, J. (1999a). Unexpected inflation and bank stock returns: the case of France 1977-1991. Journal of Banking and Finance, 23, 939-953.

Lee, C. C., Chen, M. P., \& Chang, C. H. (2013). Dynamic relationships between industry returns and stock market returns. The North American Journal of Economics and Finance Volume, 26, 119-144.

Lien, D., Tse, Y. K., Tsui, A. K. C. (2001). Evaluating the hedging performance of the constant-correlation GARCH model, Applied Financial Economics, Forthcoming.

Mojisola, O., Pointon, J., El-Masry, A. A. (2011). Exchange rate and interest rate exposure of UK industries using AR(1)-EGARCH-M Approach. Journal of Social Science Research Network.

Mok, H. M. K. (1993). Causality of interest rate, exchange rate and stock prices at stock market open and close in Hong Kong. Asia Pacific Journal of Management, 10, 123-143.

Pablo, M. M., Román, F-L., Francisco, E-S. (2014). Interest rate changes and stock returns in Spain: a wavelet analysis. Journal of BRQ Business Research Quarterly.

Pan, M. S., Fok, R. C. W., \& Liu, Y. A. (2007). Dynamic linkages between exchange rates and stock prices: evidence from East Asian markets. International Review of Economics and Finance, 16, 503-520.

Prabhath, J., \& Tsui, A. K. (2008). Exchange rate exposure of sectoral returns and volatilities: evidence from Japanese industrial sectors. Japan and the World Economy, 20, 639-660.

Reilly, F. K., Wright, D. J., \& Johnson, R. R. (2007). Analysis of the interest rate sensitivity of common stocks. Journal of Portfolio Management, 33, 85-107.

Saunders, A., \& Yourougou, P. (1990). Are banks special? The separation of banking from commerce and interest rate risk. Journal of Economic and Business, 42, 171-182.

Schwert, G. W. (1990). Stock volatility and the crash. Review of Financial Studies, 3, 77-102.

Staikouras, S. K. (2003). The Interest Rate Risk Exposure of Financial Intermediaries: A Review of the Theory and Empirical Evidence Financial Markets, Institutions \& Instruments, 12(4), 257-289.

Staikouras, S. K. (2006). Financial Intermediaries and Interest Rate Risk: II Financial Markets, Institutions \& Instruments, 15(5), 225-272.

Stone, B. K. (1974). Systematic interest rate risk in a two-index model of returns. Journal of Financial and Quantitative Analysis, 9, 709-721.

Wensheng, D., Yiqun, D., Yonghong, T. (2010). Researches on exchange rate risk of listed companies evidence from non-financial listed companies of Beijing. http://www.seiofbluemountain.com/upload/ product/201108/2011gszlhy03a12. 